OPEN ACCESS

Edited by:

Wanjun Chen,

National Institutes of Health

$(\mathrm{NIH})$, United States

Reviewed by:

Jingying Zhou,

The Chinese University of Hong

Kong, Hong Kong

Eui-Cheol Shin,

Korea Advanced Institute of Science

and Technology, South Korea

*Correspondence:

Jinlin Hou

jlhousmu@163.com;

Hongkai Wu

wuhongkai@gmail.com;

Zhanhui Wang

w851419@yahoo.com

these authors have contributed equally to this work.

Specialty section:

This article was submitted

to T Cell Biology,

a section of the journal

Frontiers in Immunology

Received: 15 June 2017

Accepted: 30 August 2017 Published: 14 September 2017

Citation:

Xu Y, Liu Y, Zhao M, Chen Y, Xie C, Gong $M$, Deng H, Li X, Sun J, Hou J,

Wu H and Wang Z (2017) Dynamic Perturbations of CD4 and CD8 T Cell

Receptor Repertoires in Chronic

Hepatitis B Patients upon Oral

Antiviral Therapy.

Front. Immunol. 8:1142.

doi: 10.3389/fimmu.2017.01142

\section{Dynamic Perturbations of CD4 and CD8 T Cell Receptor Repertoires in Chronic Hepatitis B Patients upon Oral Antiviral Therapy}

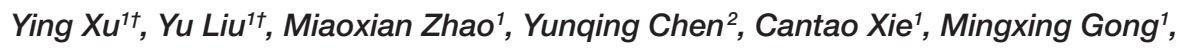
Haohui Deng ${ }^{1}$, Xueying $\mathrm{Li}^{1}$, Jian Sun ${ }^{1}$, Jinlin Hou ${ }^{1 *}$, Hongkai Wu ${ }^{3 *}$ and Zhanhui Wang ${ }^{1 *}$

'State Key Laboratory of Organ Failure Research, Guangdong Provincial Key Laboratory of Viral Hepatitis Research, Department of Infectious Diseases and Hepatology Unit, Nanfang Hospital, Southern Medical University, Guangzhou, China, ${ }^{2}$ Department of Infectious Diseases, The First Hospital of Jiaxing, Jiaxing, China, ${ }^{3}$ State Key Laboratory of Respiratory Disease, The First Affiliated Hospital of Guangzhou Medical University, Guangzhou Medical University, Guangzhou, China

Long-term treatment with nucleos(t)ide analogs (NUCs) can improve the antiviral T cell response in chronic hepatitis $\mathrm{B}(\mathrm{CHB})$ patients. Whether and to what extent the $\mathrm{T}$ cell response is improved by NUCs in the early stage leading to hepatitis $\mathrm{B}$ e antigen $(\mathrm{HBeAg})$ seroconversion remain to be clarified. A total of $22 \mathrm{CHB}$ patients undergoing 2-year telbivudine-based therapy were enrolled, including 10 exhibiting a complete response (CR) and 12 exhibiting a non-complete response (NCR) according to HBeAg seroconversion at week 52. Peripheral $\mathrm{CD} 4^{+}$and $\mathrm{CD} 8^{+} \mathrm{T}$ cells were sorted at baseline, weeks 12 , and 24 . The T cell receptor $\beta$ chain (TCR $\beta$ ) complementarity-determining region 3 was analyzed by unbiased high-throughput sequencing. Compared with NCR group, patients in CR group had a much lower percentage of persistent clonotypes $(P<0.001)$ but remarkably higher percentages of new and expanded clonotypes $(P<0.05)$ between any two time points for both CD4 and CD8 subsets. The CD4 $T$ cells exhibited a stronger response than CD8 population in the patients. The number of new and expanded clonotypes was inversely associated with the decline of viral antigen. In conclusion, NUC-based therapy induces a broad and vigorous T cell response with rapid decline of antigenemia during the early stage of treatment. A broad $\mathrm{T}$ cell expansion is crucial for HBeAg seroconversion. Our findings suggest that the potent suppression of hepatitis B virus replication by NUC monotherapy complemented with additional immunomodulatory strategies may increase the likelihood of a functional cure for $\mathrm{CHB}$ in the future.

Keywords: high-throughput sequencing, chronic hepatitis B infection, nucleos(t)ide analogs, hepatitis B e antigen seroconversion, $\mathrm{T}$ cell receptor

Abbreviations: ALT, alanine aminotransferase; CDR3, complementarity-determining region 3; $\mathrm{CHB}$, chronic hepatitis $\mathrm{B}$; $\mathrm{CR}$, complete response; HBeAg, hepatitis B e antigen; HBV, hepatitis B virus; NCR, non-complete response; NUCs, nucleos $(\mathrm{t})$ ide analogs; PBMCs, peripheral blood mononuclear cells; TCR $\beta$, T cell receptor $\beta$ chain; IFN, interferon. 


\section{INTRODUCTION}

The currently available options for chronic hepatitis B (CHB) treatment include nucleos(t)ide analogs (NUCs) and interferon- $\alpha$ (IFN- $\alpha$ ). One of the goals of antiviral therapy in hepatitis B e antigen ( $\mathrm{HBeAg}$ )-positive patients is achieving $\mathrm{HBeAg}$ seroconversion, an indicator of a more favorable outcome of the antiviral therapy (1). However, approximately only $20-30 \%$ of HBeAg-positive patients achieve HBeAg seroconversion during 2-3 years of continuous NUC treatment $(2,3)$. Many studies have defined the robust and multiepitope-specific CD4 and CD8 $\mathrm{T}$ cell responses that mediate the spontaneous clearance of an acute hepatitis B virus (HBV) infection (4-6), whereas weak or exhausted $\mathrm{T}$ cell function occurs during a chronic HBV infection, leading to persistent infection (7-10). Nevertheless, multiple studies have shown an increased frequency and improved function of HBV-specific CD4 and CD8 T cells in CHB patients after NUC therapy (11-19), although the restoration of functional $\mathrm{T}$ cells is transient and not vigorous enough to control HBV for a prolonged period (11).

The antigen specificity of a $\mathrm{T}$ cell is determined by the $\mathrm{T}$ cell receptor (TCR) expressed on its surface. Over $90 \%$ of TCRs are composed of $\alpha$ and $\beta$ chains (20). The massive diversity of TCRs is due to the somatic rearrangement of various V-J gene segments of the $\alpha$ chain and V-D-J gene segments of the $\beta$ chain (21). Furthermore, the variable addition and deletion of nucleotides at the junctions between the gene segments contributes to greater diversity of the TCR repertoire (22). Complementaritydetermining region 3 (CDR3) in the T cell receptor $\beta$ chain (TCR $\beta$ ), which falls at the junction between the V-D-J gene segments, forms the center of the TCR antigen-binding site. Therefore, the molecular features of CDR3s can be used to monitor $\mathrm{T}$ cell response to antigens.

$\mathrm{T}$ cell receptor diversity is closely associated with the effective elimination of pathogens by the host immune system, treatment effectiveness and the outcome of multiple diseases (23-27). Several studies have investigated TCRs in HBV-infected patients. Skewed variable TCR patterns were found in different $\mathrm{T}$ cell subsets of patients with acute hepatitis B and during different clinical phases of CHB compared with healthy controls (28-33). In addition, several researchers have studied the relationship between TCRs and antiviral treatment outcomes in CHB patients $(34,35)$. However, all these studies assessed the TCR using conventional methods, such as quantitative PCR, CDR3 spectratyping, and Sanger sequencing, all of which yield extremely limited information, given that only the length or a small number of TCR CDR3 sequences can be determined.

The high-throughput sequencing of TCRs allows in-depth profiling of the $\mathrm{T}$ cell repertoire, thereby providing an unprecedented amount of information at the sequence level for any given sample. Additionally, the composition, distribution, and diversity of CDR3s can be elucidated and the relative levels quantified. To date, a very limited number of studies have investigated the TCR repertoire in $\mathrm{CHB}$ patients using high-throughput sequencing $(36,37)$, and only the usage of $\mathrm{V} \beta$ and $\mathrm{J} \beta$ gene segments was analyzed in these studies. Furthermore, while previous studies of NUC-treated patients have shown the restoration of $\mathrm{T}$ cell function by stimulating peripheral blood mononuclear cells (PBMCs) and staining for cytokines, the type and extent of antiviral $\mathrm{T}$ cell response that required to be restored to achieve control of a chronic HBV infection upon antiviral therapy remain unclear. In this study, we aimed to elucidate the characteristics and dynamic perturbations of the CD4 and CD8 TCR repertoires that were associated with a decline in HBV antigen in CHB patients treated with NUCs. We conducted a longitudinal study to quantify dynamic changes in the global CD4 and CD8 TCR CDR3 repertoires during an early stage of NUC therapy in CHB patients with or without $\mathrm{HBeAg}$ seroconversion. With an in-depth molecular analysis, our results provide a new quantitative insight into understanding $\mathrm{T}$ cell responses in CHB patients undergoing NUC treatment. Our data reveal the importance of a broad $\mathrm{T}$ cell expansion along with a decline in viral antigen to control $\mathrm{HBV}$ in $\mathrm{CHB}$ patients undergoing NUC therapy, especially during the first 12 weeks of treatment.

\section{MATERIALS AND METHODS}

\section{Patients}

A total of $22 \mathrm{HBeAg}$-positive CHB patients were enrolled from Nanfang Hospital (Guangzhou, China). All the patients participated in a prospective clinical trial of telbivudine-based therapy $(38,39)$. The inclusion criteria were as follows: hepatitis B surface antigen (HBsAg)-positive status for at least 6 months; $\mathrm{HBeAg}$ positive and anti-HBe-negative; HBV DNA $>5 \log _{10}$ copies/mL; alanine aminotransferase (ALT) $\geq 2$ and $<10 \times$ the upper normal limit; and without any antiviral treatment within 6 or 12 months. The exclusion criteria have been described elsewhere (38). The 22 patients were subdivided into complete response $(\mathrm{CR}, n=10)$ and non-complete response (NCR, $n=12$ ) groups based on $\mathrm{HBeAg}$ status and HBV DNA level at weeks 52 and 104 of treatment. Patients in the CR group achieved $\mathrm{HBeAg}$ seroconversion and had a level of serum HBV DNA of $<300$ copies/mL at week 52, which was sustained at week 104, while patients in the NCR group maintained HBeAg positivity and an HBV DNA level >300 copies $/ \mathrm{mL}$ at weeks 52 and 104. All the patients achieved normal ALT levels at weeks 52 and 104. The baseline characteristics of the patients are provided in Table 1. This study was conducted according to the Declaration of Helsinki and was approved by the Ethics Committee of Nanfang Hospital. Written informed consent was obtained from all the patients.

\section{Assays for Serological Markers and HBV DNA}

Serological markers for HBV were detected using ARCHITECT i2000SR (Abbott Laboratories, Chicago, IL, USA). The HBV DNA level was quantified using the Roche COBAS Taqman platform (with a lower limit of detection of $12 \mathrm{IU} / \mathrm{mL}$ or 69.84 copies $/ \mathrm{mL}$ ). Serum ALT levels were assessed at local laboratories according to standard procedures. HBV genotypes were identified by $\mathrm{S}$ gene sequencing.

\section{Isolation of PBMCs and Cell Sorting}

Peripheral blood samples were collected at baseline and at weeks 12 and 24 of treatment. PBMCs were isolated by density-gradient 
TABLE 1 | Clinical characteristics of enrolled patients at baseline.

\begin{tabular}{lccc}
\hline & CR $(\boldsymbol{N}=\mathbf{1 0})$ & NCR $(\boldsymbol{N}=\mathbf{1 2})$ & $P$-value \\
\hline Gender (male/female) $^{\mathrm{b}}$ & $8 / 2$ & $12 / 0$ & 0.195 \\
Age, years & $26(21.75-27.25)$ & $29(23.5-35.25)$ & 0.185 \\
Hepatitis B virus (HBV) & $7 / 3$ & $8 / 4$ & 1.000 \\
Genotype (B/C) & & & \\
ALT (ULN) & $2.95(2.20-6.49)$ & $3.28(2.36-5.56)$ & 0.947 \\
HBV DNA, $\log _{10} \mathrm{Copies} / \mathrm{mL}^{\mathrm{a}}$ & $8.58(6.92-9.08)$ & $9.07(8.62-9.56)$ & 0.056 \\
HBsAg, $\log _{10} \mathrm{IU} / \mathrm{mL}^{\mathrm{a}}$ & $4.43(3.86-4.56)$ & $4.88(4.49-5.06)$ & 0.015 \\
HBeAg, $\log _{10} \mathrm{PEIU} / \mathrm{mL}^{\mathrm{a}}$ & $2.39(1.61-3.34)$ & $3.17(2.85-3.31)$ & 0.391 \\
Anti-HBc, $\log _{10} \mathrm{IU} / \mathrm{mL}^{\mathrm{a}}$ & $4.35(4.21-4.51)$ & $4.06(3.92-4.26)$ & 0.018 \\
\hline
\end{tabular}

Median (25-75\% percentile), Mann-Whitney U test.

${ }^{b}$ Fisher's exact test.

CR, complete response, patients with $\mathrm{HBeAg}$ seroconversion at week 52 and 104; NCR, non-complete response; patients without HBeAg seroconversion at week 52 or 104; ALT, alanine aminotransferase; HBsAg, hepatitis B surface antigen; HBeAg, hepatitis $B$ e antigen; anti-HBc, hepatitis B core antibody; ULN, upper limit of normal.

centrifugation according to standard protocols and were cryopreserved in liquid nitrogen until analysis. For cell sorting, the PBMCs $\left(0.1-1 \times 10^{7}\right)$ were thawed, washed with RPMI-1640 containing 10-20\% FBS, and then treated with $100 \mathrm{U} / \mathrm{mL}$ DNase I (Roche) to degrade DNA released from dead or dying cells in order to reduce cell clumps. The remaining PBMCs were labeled with Live/Dead (Life Technologies), CD4-APC, CD8-FITC, and CD19-PE (BD Biosciences) and were sorted using a FACSAria III Cell Sorter (BD Biosciences). The staining profile and gating strategy for cell sorting are shown in Figure S1 in Supplementary Material.

\section{RNA Preparation and TCR $\beta$ Deep Sequencing}

Total RNA was extracted from the sorted lymphocytes using TRIzol reagent (Invitrogen). Unbiased TCR $\beta$ libraries were prepared using 5' rapid amplification of cDNA ends strategy, as previously described (40), followed by Illumina HiSeq sequencing.

\section{TCR $\beta$ Sequence Analysis}

$\mathrm{T}$ cell receptor $\beta$ chain $\mathrm{V}, \mathrm{D}$, and $\mathrm{J}$ gene identification, CDR3 sequence extraction and error corrections in clean reads were performed using MiXCR (41). The productive TCR $\beta$ sequence reads were filtered by removing: (i) any read with CDR3s shorter than 4 amino acids; (ii) CDR3 contigs with a length that was not a multiple of 3; and (iii) contigs containing stop codons. TCR diversity was evaluated by Shannon entropy (42). A method for the analysis of dynamic changes in the $\mathrm{T}$ cell repertoire has been previously described (26) and was used with some modifications. First, all clonotypes (i.e., unique amino acid TCR $\beta$ sequences) were assigned to four classes according to their $\log _{10}$-transformed frequencies as follows: $1+$ referred to clonotypes in the lowest $\log _{10}$ frequency range; $2+$ denoted clonotypes occupying $95 \%$ of the total repertoire and excluded clonotypes in 1+; $4+$ referred to the most abundant 100 clonotypes; and $3+$ referred to the remaining clonotypes that were not classified as $1+, 2+$, or $4+$. The cumulative frequency of each clonotype class (i.e., the clone size of each individual clonotype) was analyzed by calculating the sum of the same class of clonotypes at the indicated time point. Finally, each clonotype was tracked over the treatment time points and sorted into one of five categories: ablated (clones not present at later time points); depleted (clones downgraded to lower frequency classes); persistent (clones that were stable in the same class between time points); expanded (clones upgraded from a lower to a higher frequency class); or new (clones not present at prior time points).

\section{Phylogenetic Analysis}

Phylogenetic tree was constructed according to the neighborjoining method using Mega 7.0 (43). Bootstrap support was determined by 500 resamplings of the sequences.

\section{Statistical Analysis}

The data were expressed as medians. The Mann-Whitney $U$-test and Fisher's exact test were used for two-group comparisons. The Friedman's $M$ test was used to compare values among three time points during treatment. The $\mathrm{q}$ test was subsequently used to determine which two values were significantly different if the $P$-value was $<0.05$ for Friedman's $M$ test. The Spearman's rank order correlation coefficient was used to calculate correlations. Two-sided $P$-values $<0.05$ were considered statistically significant.

\section{RESULTS}

\section{Patient Characteristics}

At baseline, there were no significant differences in age, gender, genotype, or the levels of HBeAg or HBV DNA between the CR and NCR patients; differences were observed in HBsAg and hepatitis B core antibody levels between the groups (Table 1). The dynamic changes in HBV serological markers are shown in Figure S2 in Supplementary Material. No patients achieved HBsAg loss at week 104. The number of sorted cells in each T cell subset was also comparable between the two groups of patients at each time point (Table S1 in Supplementary Material).

\section{Patient TCR $\beta$ Repertoire Profiles}

A total of 229,756,079 and 153,420,480 clean reads were obtained from CD4 and CD8 T cells, respectively, by high-throughput sequencing. After filtering the data with MiXCR, we obtained $194,195,801$ and $119,574,667$ productive TCR $\beta$ reads from CD4 and CD8 T cells, respectively, which were assembled for a total of 27,228 and 25,035 unique CDR3 nucleotide (nt) clonotypes encoding 25,840 and 23,393 unique CDR3 amino acid (aa) clonotypes per sample, respectively. Details of the TCR sequences are displayed in Table S1 in Supplementary Material. Both the clean reads and total unique TCR $\beta$ reads at each of the three time points were comparable between the CR and NCR groups in each cell subset.

\section{The Usage of $V \boldsymbol{\beta}$ and $\mathrm{J} \beta$ Gene Segments}

In the CD4 T cells, $64 \mathrm{~V} \beta$ and $14 \mathrm{~J} \beta$ gene segments as well as 790 VJ and 2,266 VDJ gene combinations were identified. In CD8 T cells, $64 \mathrm{~V} \beta, 14 \mathrm{~J} \beta, 795 \mathrm{VJ}$, and 2,266 VDJ gene combinations were identified. The usage patterns of $\mathrm{V} \beta$ and $\mathrm{J} \beta$ gene segments in 
each sample at each time point are shown in Figure 1. No obvious preferential usage of $\mathrm{V} \beta$ and $\mathrm{J} \beta$ gene segments was observed between the CR and NCR groups in either the CD4 or CD8 subset. Nevertheless, we found two to eight V $\beta$ segments with significantly different expression profiles between the CR and NCR groups in each T cell subset at each time point (Figure S3 in Supplementary Material). The V $\beta$ gene segments in CD4 T cells clustered nearly distinctively between the CR and NCR groups based on principal component analysis; however, no similar phenomenon was observed in CD8 $\mathrm{T}$ cells (Figures S4A,B in Supplementary Material).

\section{Differing Diversity but Similar Patterns of Change in CD4 and CD8 T Cells in CR and NCR Patients}

The numbers of unique VDJ combinations, aa clonotypes, as well as the Shannon entropy values, were relatively lower in CD4 subset (Figures 2A-C) but were higher in CD8 subset (Figures 2D-F) in the CR patients at baseline, week 12 and week 24 of treatment, although statistically significant differences were observed only at week 12 for CD4 cells and at baseline for CD8 cells. This result indicates that there was a relatively higher diversity in CD8 $\mathrm{T}$ cells, while the CD4 cells exhibited reduced diversity in CR patients compared with the NCR patients. Compared with NCR group, the relatively lower level of diversity in CD4 cells in the CR patients at baseline reached significance at week 12, as indicated by the VDJ combinations ( 1,423 vs 1,$570 ; P=0.035)$, aa clonotypes $(17,255$ vs 27,$840 ; P=0.03)$, and Shannon entropy values ( 10.80 vs $12.78 ; P=0.041)$. The diversity of CD4 TCR $\beta$ repertoire significantly decreased from baseline to week 12 during treatment in the CR patients ( 12.30 vs $10.80 ; P=0.022$; Figure $2 \mathrm{C}$ ). However, the significantly higher number of aa clonotypes (20,710 vs 14,$600 ; P=0.041)$ in CD8 cells of the CR patients at baseline were comparable to those in the NCR patients at week 12. In accord with this, the HBV DNA, HBsAg, and HBeAg levels declined rapidly during the first 12 weeks of treatment compared with the other time points (Figure S2 in Supplementary Material). Collectively, these data suggest a trend that the diversity of CD 4 and CD8 TCR $\beta$ repertoires were changed during the early stage of NUC therapy along with the rapid decline of viral antigen levels compared with the NCR patients, although a significant difference was only observed in CD4 T cells.

\section{Clone Distribution of the CD4 and CD8 TCR Repertoires}

To determine how the TCR $\beta$ repertoires of $\mathrm{CD}^{+}$and $\mathrm{CD} 8^{+}$ $\mathrm{T}$ cells changed with NUC treatment, we first tracked the dynamic changes in all clones at baseline, weeks 12 , and 24 . The
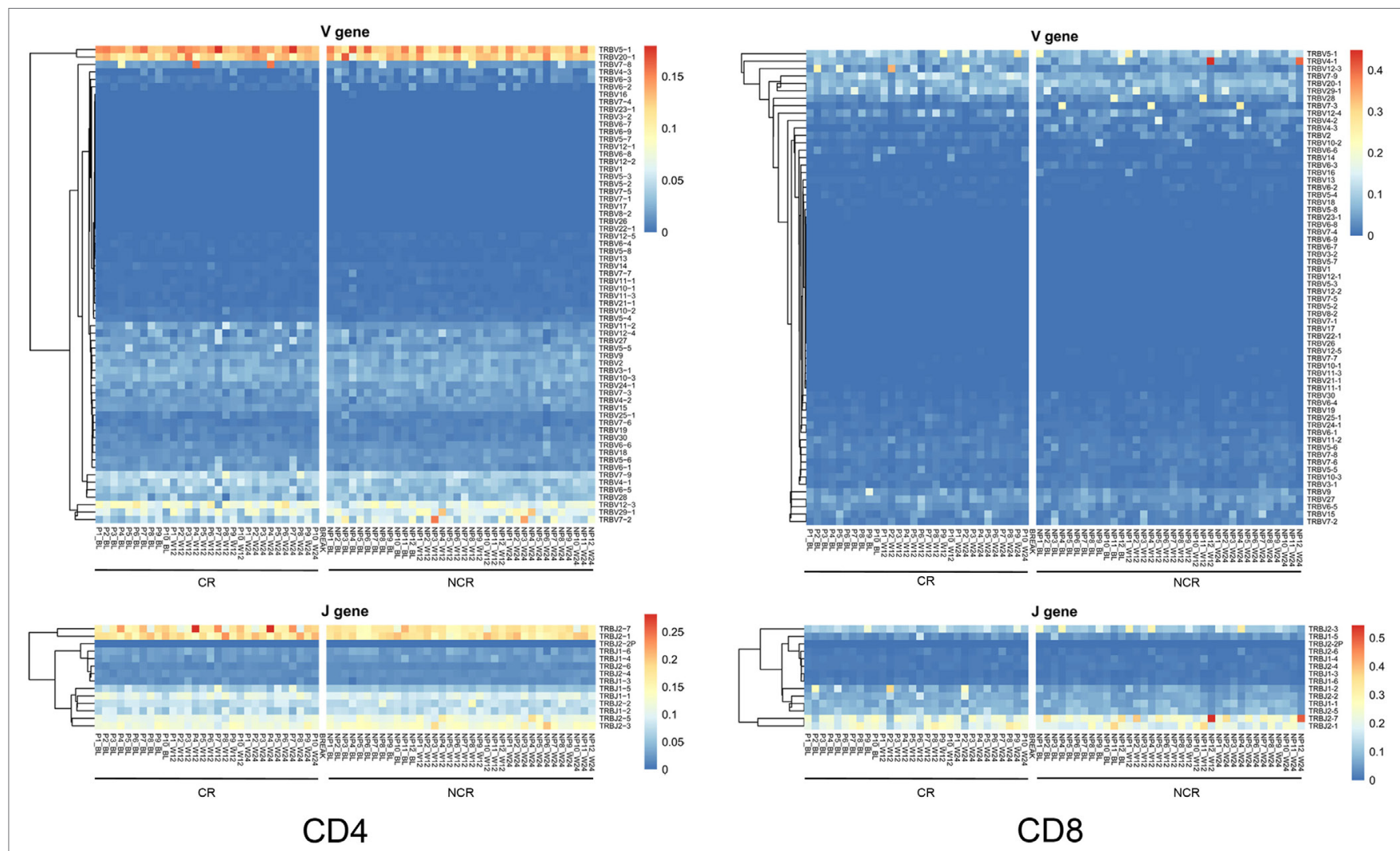

FIGURE 1 | Heatmap of $\mathrm{V} \beta$ and $J \beta$ gene segments usage in CD4 and CD8 T cells in the complete response (CR) and non-complete response (NCR) patient groups. The heatmap bar indicates the usage frequency of the $\mathrm{V} \beta$ or $\mathrm{J} \beta$ gene segments in each sample. The sample numbers of the CR and NCR groups are indicated on the $x$-axis. 


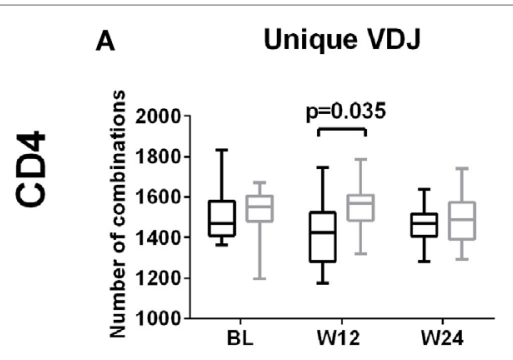

D

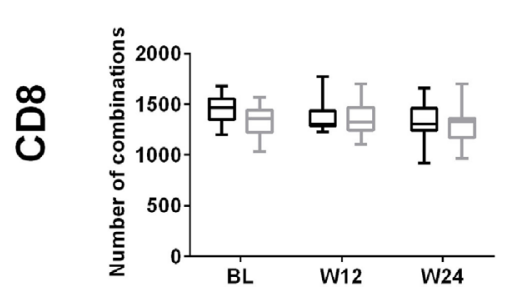

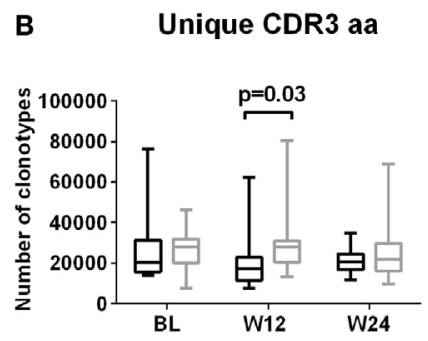

E

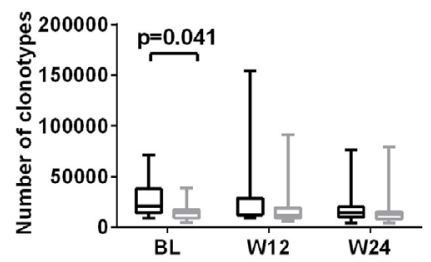

C Shannon entropy

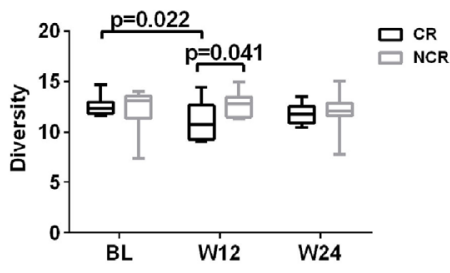

F Shannon entropy

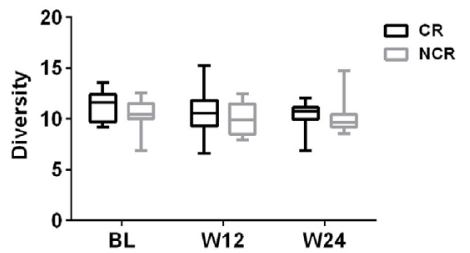

FIGURE 2 | Diversity of CD4 and CD8 T cell repertoires during early nucleos(t)ide analog treatment. Longitudinal analysis of the number of unique VDJ combinations (A,D), complementarity-determining region 3 (CDR3) aa clonotypes (B,E), and Shannon entropy values (C,F) in CD4 and CD8 T cells in the complete response (CR) and non-complete response (NCR) groups, respectively; $P$-values less than 0.05 are shown. The $x$-axis represents treatment timepoints. BL, baseline; W12, week 12; W24, week 24.

individual clones in both CD4 and CD8 cells exhibited remarkable changes in all the patients (Figure S5 in Supplementary Material). When changes in the dynamic frequency of the most highly abundant clones (the top 5, 10, 20, and 50) were analyzed separately, some $\mathrm{T}$ cells showed a persistent increase, while others exhibited an increase followed by a decrease or vice versa (Figure S6 in Supplementary Material). We further analyzed the dynamic changes in each clonotypic frequency by stratifying all the clonotypes into four classes according to their frequencies (details are provided in the Section "Materials and Methods"). In all the patients, the vast majority of $\mathrm{T}$ cell clones belonged to class $1+$ or $2+$ (Figure 3A). The 100 most abundant clonotypes in CD8 T cells accounted for a greater proportion of the TCR $\beta$ repertoire compared with those present in CD4 cells, suggesting greater expansion of the most abundant clones in CD8 T cells (Figure 3B). Nevertheless, the CR and NCR groups had similar cumulative frequencies across all four classes at each time point for both cell subsets (Figure 3C).

\section{CR Patients Were Characterized by Greater Perturbations of Both CD4 and CD8 TCR Repertoires}

To further determine how the frequency of CD 4 and CD8 TCR $\beta$ repertoires changed, all the clones in classes $1+$ through $4+$ in each patient were assigned to one of five categories-ablated, depleted, persistent, expanded, or new-according to the criteria described in the Section "Materials and Methods." The percentage of persistent unique clonotypes was the highest compared with that of the other four categories between any two time points in either subset (Figure 4A). However, the median cumulative frequencies of persistent clonotypes in CD4 and CD8 cells were only 10.68 and $28.84 \%$, respectively (Figure 4B). The cumulative frequency of new and expanded clonotypes in CD4 was higher than that in CD8 subset in the patients (Figure 4B). The new and expanded clonotypes, which were 4.05 and $3.65 \%$ of the total CD4 and CD8 clonotypes, respectively, constituted 87.76 and $69.90 \%$ of the CD4 and CD8 repertoires, respectively (Figures 4A,B).

We next compared the percentage and cumulative frequency of each category of $\mathrm{T}$ cell clone between the CR and NCR patients. The percentage of persistent clonotypes was lower in CR than in the NCR group between any two time points in both CD 4 and CD8 subsets (all $P<0.001$; Figures 4A,C). In contrast, patients in the CR group had much higher combined percentages of new and expanded clonotypes than those in the NCR group between any two time points in both CD4 and CD8 cells (all $P<0.05$; Figures $4 A, C$ ). The number of ablated clonotypes in CD4 T cells at week 12 was much higher than that of newly appearing clonotypes compared with baseline $(P=0.021)$, leading to a lower diversity of CD4 cells at week 12 in CR group. When clone size was considered, the CR group exhibited a higher cumulative frequency of persistent clones (all $P<0.05$ ) and a lower combined cumulative frequency of new and expanded clonotypes in CD4 T cells during the first 12 weeks of treatment (70.14 vs $89.11 \% ; P=0.021$ ), while no difference was observed in the cumulative frequency of any category clones among the CD8 T cells (Figure 4C).

Taken together, these results indicate that a turnover of the TCR $\beta$ repertoire occurred in both $\mathrm{CD}^{+}$and $\mathrm{CD}^{+} \mathrm{T}$ cells of the CHB patients undergoing NUC treatment. Patients with a CR underwent more profound perturbations and broader clonal expansions of both the CD4 and CD8 T cell repertoires, but the clone size of each new and expanded clonotype was smaller. 

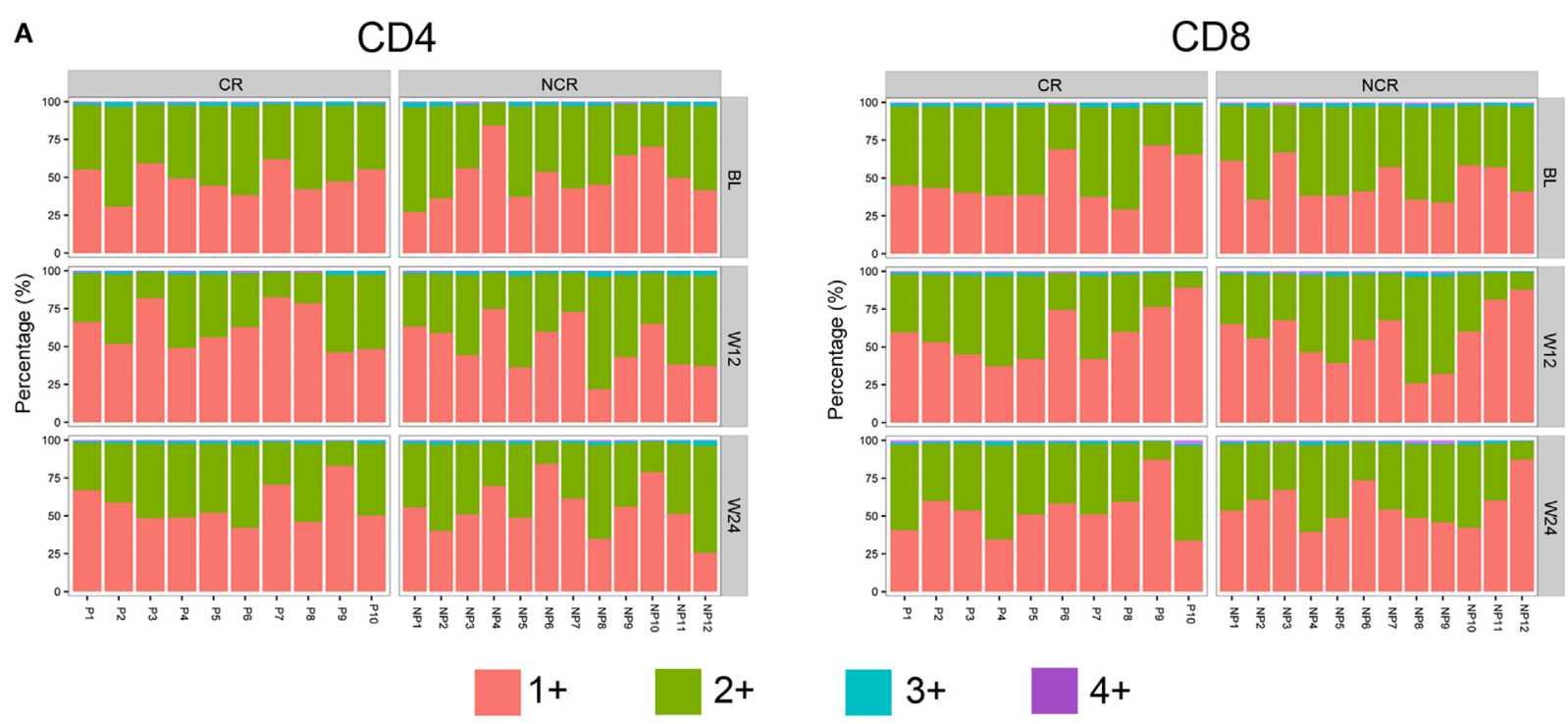

B

CD4
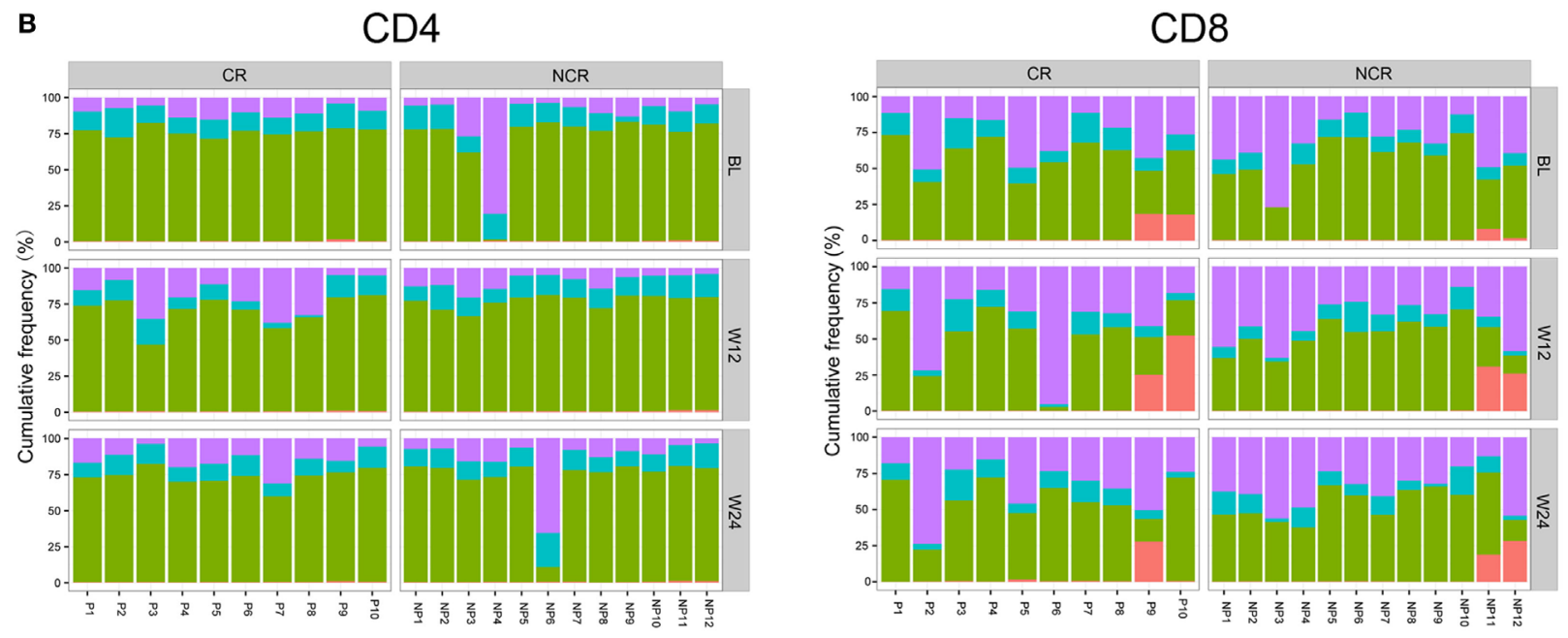

C
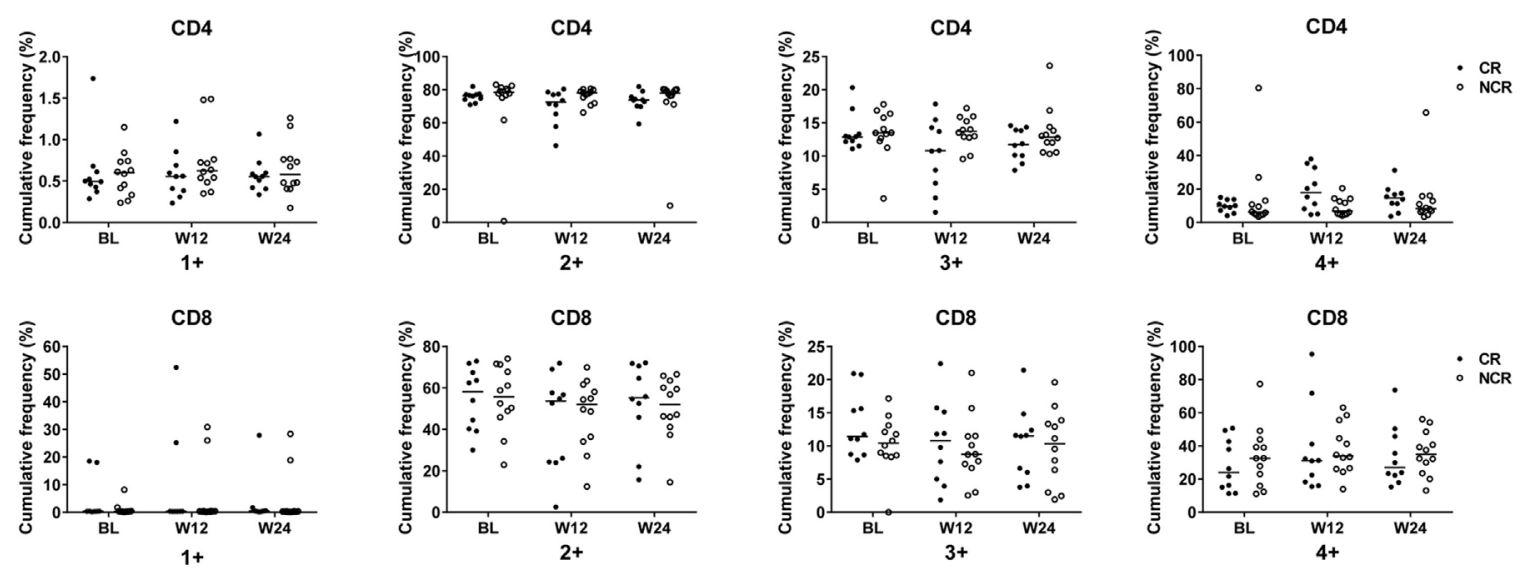

FIGURE 3 | Clone distribution of CD4 and CD8 T cells in the chronic hepatitis B patients at baseline, week 12, and week 24 of treatment. Each CD4 and CD8 clonotype was assigned to one of four classes at each time point based on the frequency of the clonotype, and the percentage of unique clonotypes (A) and the cumulative frequency of clonotypes (B) within identical classes are shown. (C) Comparisons of the cumulative frequency of CD4 and CD8 clonotypes in the four classes at each time point. No significant differences were observed. The patient numbers are indicated on the $x$-axis. P, patients in complete response (CR) group; $\mathrm{NP}$, patients in non-complete response (NCR) group. 


\section{Correlation between the Decline of HBV Antigens and T Cell Expansion}

With the rapid decline in HBV DNA, HBeAg, and HBsAg levels from baseline to week 12, a correlation between viral antigen and $\mathrm{T}$ cell expansion was observed for both CD4 and CD8 $\mathrm{T}$ cells. The percentage of unique new and expanded clonotypes exhibited a negative correlation, while persistent clonotypes were positively correlated with antigen levels at week 12 . In addition, the amount of $\mathrm{HBeAg}$ reduction from baseline to week 12 was consistently and significantly associated with the percentage of new and expanded clonotypes (Table 2). These results suggest the importance of viral antigen suppression in inducing a strong $\mathrm{T}$ cell response.

\section{CDR3 aa Sequence of the Top 1 Persistent Clonotype in CD8 Cells Differentiates the CR and NCR Groups}

We next investigated whether the CR and NCR groups could be distinguished based on the CDR3 aa sequences. The CDR3 aa sequences of the most dominant clonotype (top 1) in each sample were listed separately according to CD4 or CD8. Four CR and eight NCR patients showed identical top 1 CD8 CDR3 aa sequence at all three time points in personally, while the other patients had different top 1 clonotypes for at least one time point. Interestingly, when all the top 1 CDR3 aa sequences were phylogenetically analyzed, the four patients in the $\mathrm{CR}$ group clustered separately from seven of the eight NCR patients (Figure 5).
A

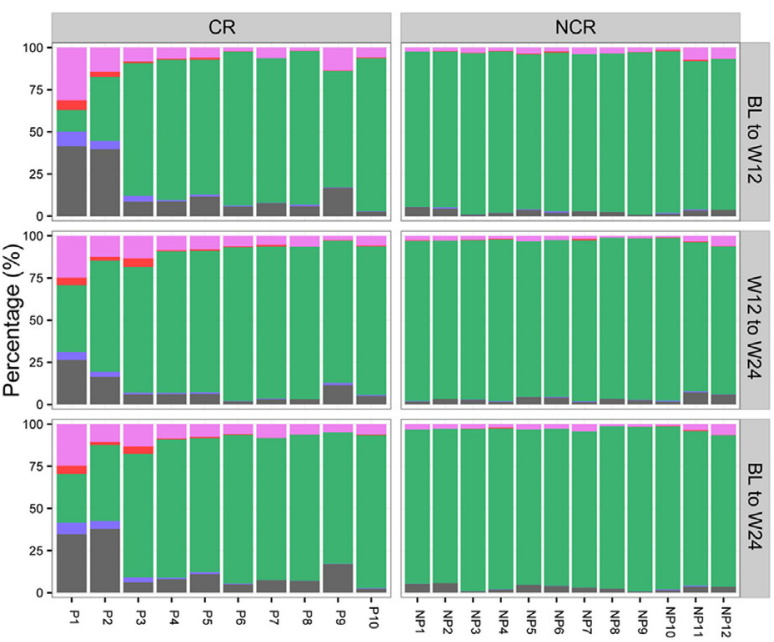

Ablated
CD4

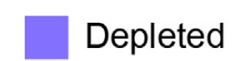

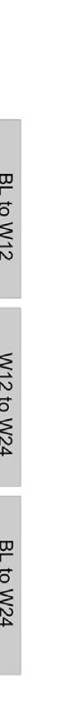

$$
\text { : }
$$
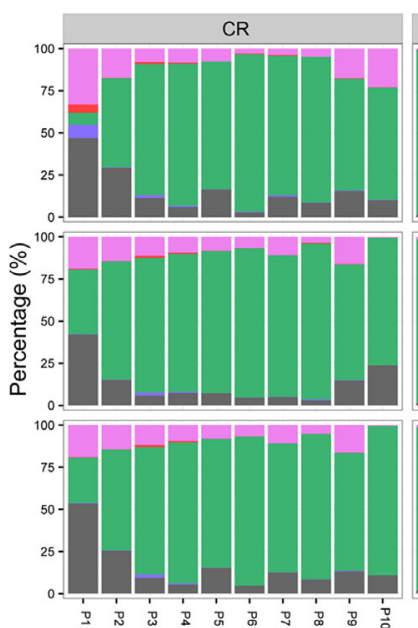

CD8

Persistent Expanded New

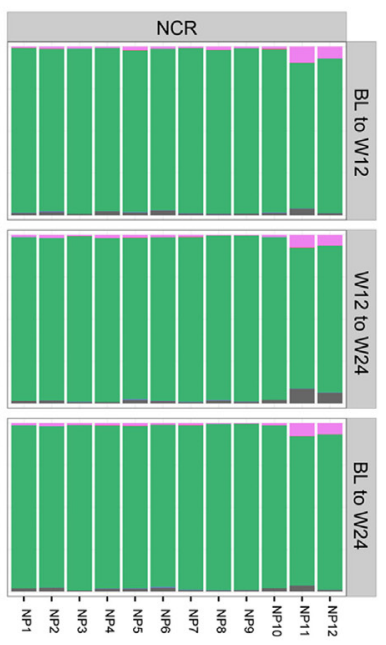

\section{CD8}
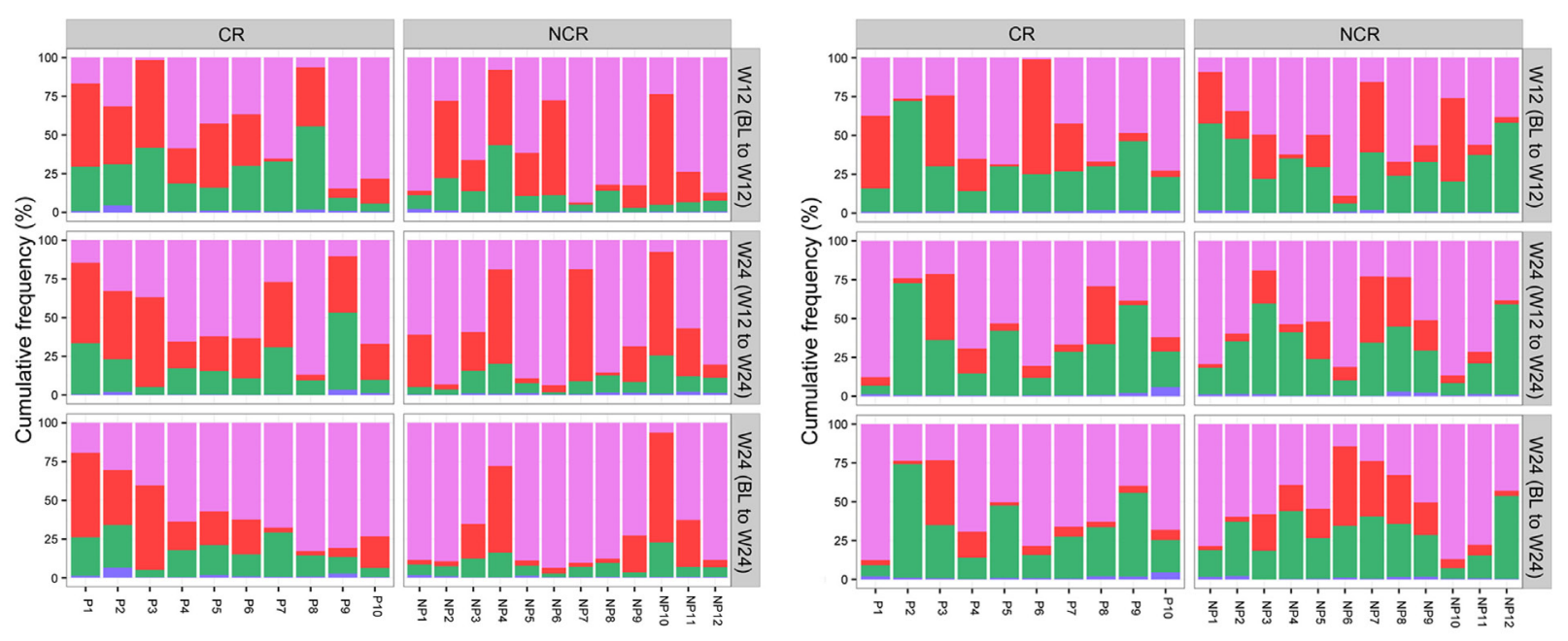


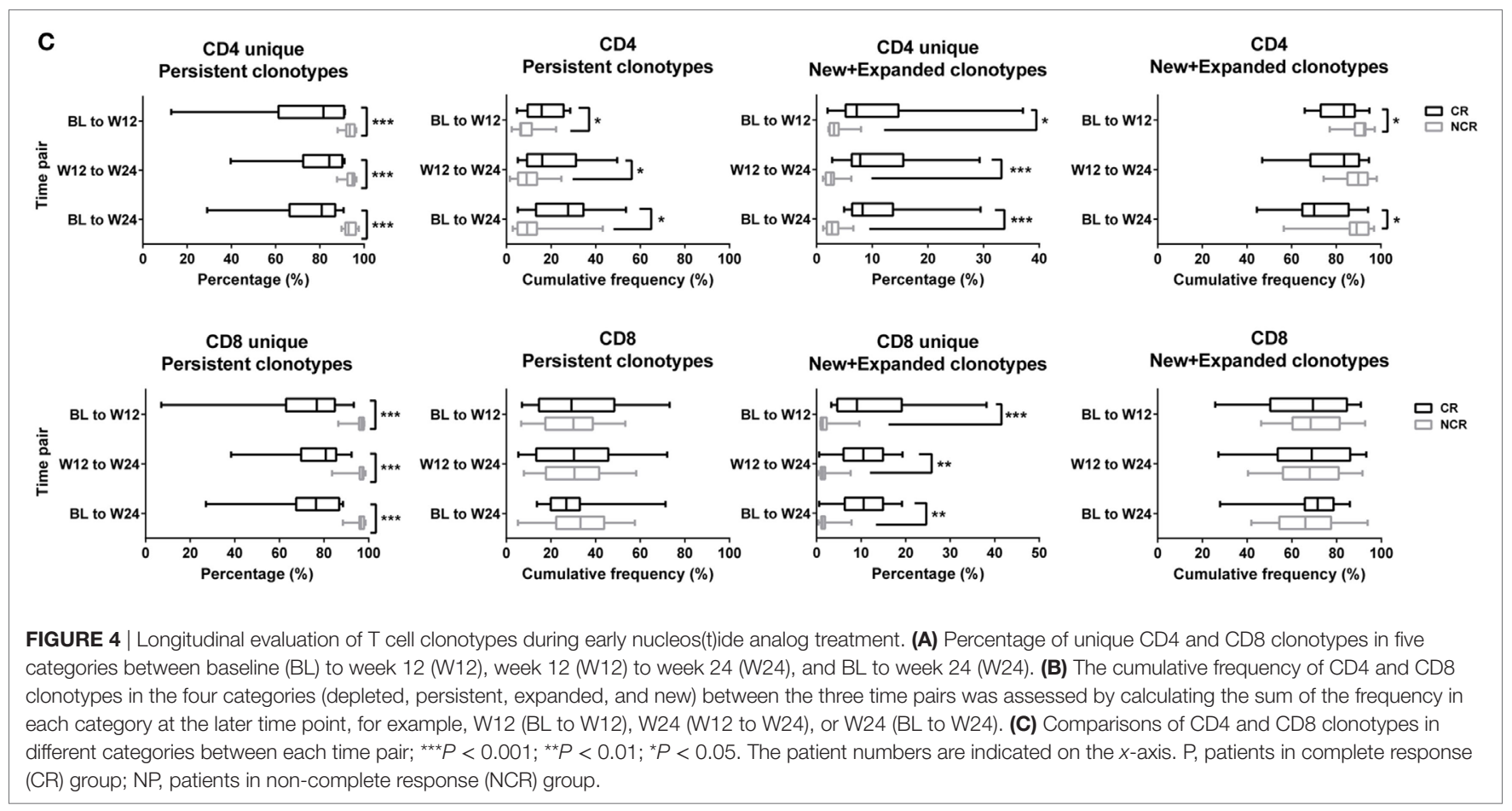

TABLE 2 | Correlation between hepatitis B virus (HBV) antigen levels and the percentage of clonotypes.

\begin{tabular}{|c|c|c|c|c|c|c|}
\hline Subject & Time point/time pair & Correlation coefficient & \multicolumn{2}{|c|}{ Persistent (BL to W12) } & \multicolumn{2}{|c|}{ New + expanded (BL to W12) } \\
\hline \multirow{3}{*}{ Hepatitis B surface antigen $\left(\log _{10} \mathrm{IU} / \mathrm{mL}\right)$} & W12 & $r$ & 0.458 & 0.548 & -0.478 & -0.509 \\
\hline & $\mathrm{BL}$ to $\mathrm{W} 12$ & $r$ & -0.155 & -0.24 & 0.292 & 0.288 \\
\hline & & $P$ value & 0.504 & 0.294 & 0.199 & 0.205 \\
\hline \multirow{2}{*}{ Hepatitis B e antigen ( $\left.\log _{10} \mathrm{PEIU} / \mathrm{mL}\right)$} & $\mathrm{BL}$ to $\mathrm{W} 12$ & r & -0.575 & -0.621 & 0.542 & 0.582 \\
\hline & & $P$ value & 0.005 & 0.002 & 0.009 & 0.004 \\
\hline \multirow[t]{3}{*}{ HBV DNA ( $\log _{10}$ copies/mL) } & W12 & $r$ & 0.552 & 0.591 & -0.419 & -0.463 \\
\hline & & $P$ value & 0.008 & 0.004 & 0.053 & 0.03 \\
\hline & $\mathrm{BL}$ to $\mathrm{W} 12$ & r & -0.226 & -0.252 & 0.045 & 0.117 \\
\hline
\end{tabular}

Spearman correlation was analyzed for samples of baseline and week 12 in total 22 patients; W12, the level of indicated marker at week 12 of treatment; BL to W12, the decline range of given HBV markers from baseline to week 12, calculating as the titer of a given marker at baseline minus that at week 12; $r$, correlation coefficient; persistent, percentage of unique persistent clonotypes; new + expanded, combined percentage of unique new and expanded clonotypes.

However, no similar phenomenon was observed in CD4 subset (data not shown). These findings suggest that the persistent top 1 CDR3 aa sequences in CD8 clonotypes were discrepant between two groups and may distinguish patients with different outcome of NUC-based treatment.

\section{DISCUSSION}

$\mathrm{T}$ cells play crucial roles in HBV infection, with vigorous and multiepitope-specific CD4 and CD8 T cell responses observed in patients with acute infection, while exhausted T-cell activity is found in cases of chronic $\mathrm{HBV}$ infection. The goal of $\mathrm{CHB}$ treatment with NUCs or IFN- $\alpha$ is to suppress HBV replication and to reduce or prevent the progression of liver disease. Accumulating evidence suggests that NUC treatment improves the antiviral $\mathrm{T}$ cell function in $\mathrm{CHB}$ patients along with the decline of antigenemia, especially in patients with HBsAg loss. Traditionally, HBV-specific T cells have been measured by stimulating PBMCs with HBV peptide pools and staining cytokines. However, the characteristics of $\mathrm{T}$ cell repertoires, including clonal composition, diversity at a sequence-level resolution, and dynamic changes, have rarely been analyzed. Therefore, what kind and to what extent of antiviral $\mathrm{T}$ cell response is required to achieve control of chronic HBV infection upon antiviral therapy remains unclear. 


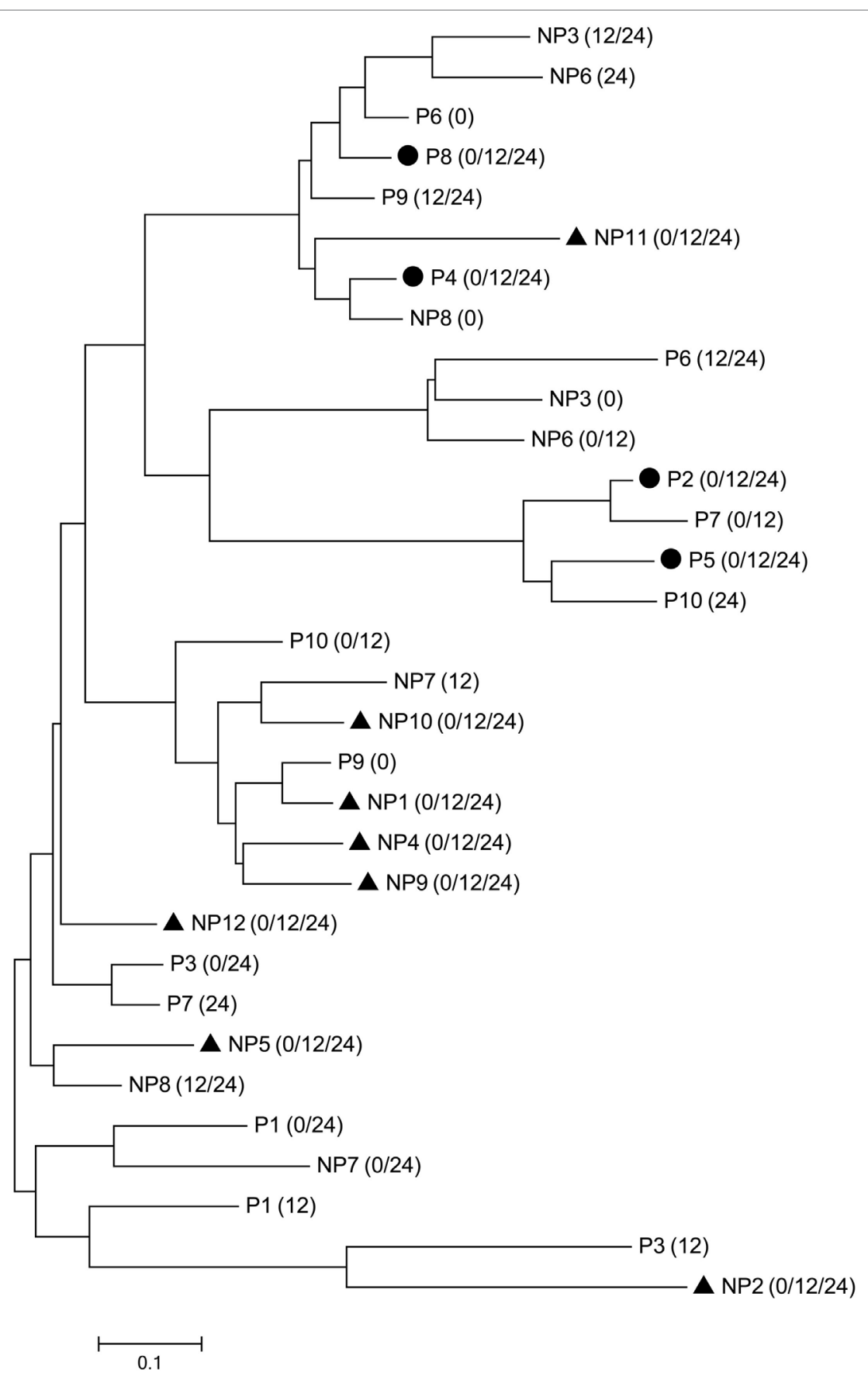

FIGURE 5 | Clustering of the top 1 CD8 clonotypes at each time point. The top 1 complementarity-determining region 3 (CDR3) sequences of the complete response (CR) and non-complete response (NCR) groups are denoted by P (CR group) or NP (NCR group) + patient ID, respectively. The time point of the CDR3 sequence is indicated in parentheses. The circle $(\mathbf{0})$ and triangle $(\boldsymbol{A})$ represent identical CDR3 sequences at baseline, week 12 , and week 24 within individual patients from the CR and NCR groups, respectively.

Accordingly, with the unbiased amplification of TCR sequences combined with high-throughput sequencing, we longitudinally investigated the dynamic changes of peripheral global CD4 and CD8 TCR repertoires at baseline, week 12 and week 24 in NUC-treated CHB patients with or without HBeAg seroconversion at weeks 52 and 104. The dynamic changes in all the T cell frequencies and numbers of clonotypes were calculated based on CDR3 sequences, allowing the quantity and quality of the T cell response by antiviral therapy to be assessed.

One important finding of this study concerns the heterogeneous dynamic change in individual clonotypes. By tracking CD4 and CD8 clonotypes during the first 24 weeks of antiviral therapy, 
we observed that the percentage of changeable clonotypes was significantly higher in CR than in the NCR patients, especially during the first 12 weeks of treatment. A large number of new and expanded clones were identified in both CD4 and CD8 T cells in the CR patients coinciding with a rapid decline in antigenemia and HBV DNA at week 12. In contrast, both the CD4 and CD8 TCR repertoires in the NCR group had a higher percentage of persistent clonotypes compared with the CR group. These data indicate a broader clonotypic $\mathrm{T}$ cell expansion and vigorous $\mathrm{T}$ cell responses of CD4 and CD8 in the CR patients compared with those in NCR patients. Consistent with this result, two important recent studies also revealed that patients with $\mathrm{HBsAg}$ loss upon antiviral therapy presented a broad and strong in vitro HBV-specific $\mathrm{T}$ cell response as assessed by analyzing cytokine production $(19,44)$. Using high-throughput sequencing and the calculation of global TCR CDR3 repertoires in PBMCs with no in vitro manipulation such as cell culture or stimulation, we quantitatively demonstrated at a great depth a robust $\mathrm{T}$ cell expansion in patients with $\mathrm{HBeAg}$ seroconversion. However, when the clone size was considered, the combined cumulative frequencies of new and expanded clonotypes in the CR group was comparable in the CD8 subset and significantly lower in the CD4 subset compared with those in the NCR group, indicating that the size of each new and expanded clonotype was restricted. The higher percentage and lower cumulative frequency of the new and expanded clonotypes in the CR patients suggest that a higher-quality and broader $\mathrm{T}$ cell expansion against multiple epitopes is more important than a larger clone size with a narrower $\mathrm{T}$ cell response for $\mathrm{HBeAg}$ seroconversion in $\mathrm{CHB}$ patients undergoing NUC therapy. Our data also demonstrate the correlation of antigen decline and clone expansion, indicating the crucial role of HBV suppression in functional T cell responses.

In the current study, we noticed that the cumulative frequency of new and expanded clonotypes was significantly higher in CD4 than in CD8 subset in the patients. We also observed differences in the patterns of change in the clonotypic composition and diversity of CD4 TCR repertoires between HBeAg seroconverters and non-seroconverters. The CD4 T cells in the CR group exhibited fewer CDR3 clonotypes in parallel with a less diverse repertoire at week 12 of treatment compared with those in the NCR group. This result is due to a greater clonal expansion of the CD4 cells in the CR patients after 12 weeks of NUC-based treatment, which replaced the ablated clones. These data suggest a more vigorous CD4 response in CR compared to the NCR patients upon NUC treatment. Recent studies have also indicated that CD4-mediated responses are significantly stronger than CD8 responses in NUC-treated patients with HBsAg loss (19). Consistent with our result, higher level of serum IL-21 (45) and an increased frequency of circulating $\mathrm{CXCR} 5{ }^{+} \mathrm{CD} 4^{+} \mathrm{T}$ cells during the first 12 weeks of NUC treatment (46) were reported to be associated with early $\mathrm{HBeAg}$ seroconversion at week 52 in $\mathrm{CHB}$ patients. Similarly, Chen et al. also revealed that effective-treated patients had an increased frequency of peripheral blood CD4 ${ }^{+}$ $\mathrm{T}$ cells at week 12 upon telbivudine therapy (15). Collectively, a broad and extensive clonal expansion of $\mathrm{CD} 4^{+} \mathrm{T}$ cells during the first 12 weeks of NUC treatment is essential to antiviral treatment outcomes of $\mathrm{CHB}$ patients.
It is well known that viral clearance is mediated by both cytolytic and non-cytolytic functions of the CD8 T cell response with the help of CD4 cells; furthermore, improved function and expansion of $\mathrm{CD} 8^{+} \mathrm{T}$ cells during NUC treatment is related to a favorable virological outcome (34). In addition to the broad new and expanded $\mathrm{T}$ cell responses, we devoted particular attention to highly abundant clonotypes among the CD8 cells. Patients in the CR group had a higher diversity of top CD8 clonotypes than did the NCR group (data not shown), indicating that a more even distribution of top clonotypes is related to HBeAg seroconversion, while oligoclonal expansion against limited antigen epitopes is likely linked to the absence of HBeAg seroconversion. Notably, based on a phylogenetic analysis, the CDR3 aa sequences of the top 1 persistent CD8 clonotypes clustered separately for the CR and NCR patients. Whether the top 1 clonotype is HBV-specific or could be used to predict the treatment outcome requires additional study.

Because a large number of new and expanded clones were identified in this study, we were unable to confirm whether these T cells were HBV-specific. Previous studies have indicated that the frequency of $\mathrm{HBV}$-specific T cells is very low in the PBMCs of CHB patients (47). Additionally, the exact phenotypic markers of HBV-specific T cells remain to be determined. This lack of information increases the difficulty of profiling HBV-specific $\mathrm{T}$ cell repertoires through cell sorting and high-throughput sequencing. Furthermore, studies have shown that the restoration of functional T cells induced by NUC therapy in CHB patients is transient. Therefore, alternative strategies are required to increase the frequency of $\mathrm{HBV}$-specific $\mathrm{T}$ cells associated with NUC therapy. One potential strategy is the adoptive transfer of engineered HBV-specific TCR-redirected autologous $\mathrm{T}$ cells to improve the immune response (48).

In conclusion, by analyzing the clonotypic composition and diversity of peripheral CD4 and CD8 TCR repertoires and tracking dynamic changes in the different clonotypes in $\mathrm{CHB}$ patients upon NUC treatment, we have shown that substantial clonal expansions of the CD4 and CD8 T cell repertoires are associated with early treatment-induced $\mathrm{HBeAg}$ seroconversion. A stronger $\mathrm{T}$ cell response is closely associated with a rapid decline in viral antigen. Therefore, the robust inhibition of $\mathrm{HBV}$ replication complemented by immunomodulatory strategies in NUC monotherapy may improve the restoration of functional $\mathrm{T}$ cells and achieve complete HBV control.

\section{ETHICS STATEMENT}

This study was conducted according to the Declaration of Helsinki, and was approved by the Ethics Committee of Nanfang Hospital. Written informed consent was obtained from all the patients.

\section{AUTHOR CONTRIBUTIONS}

$\mathrm{ZW}, \mathrm{JH}$, and YX conceived and designed experiments. YX, MZ, YL, MG, YC and CX performed the experiments. MZ, YX, MG, $\mathrm{HD}, \mathrm{XL}$ and JS collected data. HW, YX and YL analyzed the sequencing data. ZW, YX and HW interpreted the data. ZW 
and YX wrote the manuscript. ZW, JH and JS approved the final manuscript. All authors had full access to the final version of the report and agreed to the submission.

\section{FUNDING}

This work was supported by grants from the National Natural Science Foundation of China (81371802) and National Science and Technology Major Project (2012ZX10002003).

\section{SUPPLEMENTARY MATERIAL}

The Supplementary Material for this article can be found online at http://journal.frontiersin.org/article/10.3389/fimmu.2017.01142/ full\#supplementary-material.

FIGURE S1 | Flow cytometric cell-sorting strategy for isolation of $\mathrm{CD}^{+}, \mathrm{CD}^{+}$ T cells and $\mathrm{CD} 19^{+}$cells. CD4 ${ }^{+}, \mathrm{CD} 8^{+} \mathrm{T}$ cells and $\mathrm{CD} 19^{+}$cells were identified by gating on lymphocytes (A), followed by exclusion of dead cells (B) and selection of $\mathrm{CD}^{+}, \mathrm{CD}^{+} \mathrm{T}$ cells $(\mathbf{C})$ and $\mathrm{CD} 19^{+}$cells (D). The figures show representative FACS profiles of one chronic hepatitis $B(\mathrm{CHB})$ patients and the strategy used for sorting.

FIGURE S2 | The clinical information of enrolled patients during the 2-year of NUC-based treatment. Black dashed line, complete response (CR) group; black line, non-complete response (NCR) group. ALT, alanine aminotransferase; HBsAg, hepatitis B surface antigen; HBeAg, hepatitis B e antigen; Anti-HBc, hepatitis B core antibody.

\section{REFERENCES}

1. Lee HW, Lee HJ, Hwang JS, Sohn JH, Jang JY, Han KJ, et al. Lamivudine maintenance beyond one year after $\mathrm{HBeAg}$ seroconversion is a major factor for sustained virologic response in HBeAg-positive chronic hepatitis B. Hepatology (2010) 51(2):415-21. doi:10.1002/hep.23323

2. Terrault NA, Bzowej NH, Chang KM, Hwang JP, Jonas MM, Murad MH. AASLD guidelines for treatment of chronic hepatitis B. Hepatology (2016) 63(1):261-83. doi:10.1002/hep.28156

3. Chinese Society of Hepatology CMA, Chinese Society of Infectious Diseases CMA, Hou JL, Lai W. [The guideline of prevention and treatment for chronic hepatitis B: a 2015 update]. Zhonghua Gan Zang Bing Za Zhi (2015) 23(12):888-905. doi:10.3760/cma.j.issn.1007-3418.2015.12.002

4. Thimme R, Wieland S, Steiger C, Ghrayeb J, Reimann KA, Purcell RH, et al. $\mathrm{CD}^{+} \mathrm{T}$ cells mediate viral clearance and disease pathogenesis during acute hepatitis B virus infection. J Virol (2003) 77(1):68-76. doi:10.1128/ JVI.77.1.68-76.2003

5. Chang JJ, Lewin SR. Immunopathogenesis of hepatitis B virus infection. Immunol Cell Biol (2007) 85(1):16-23. doi:10.1038/sj.icb.7100009

6. Rehermann B, Nascimbeni M. Immunology of hepatitis B virus and hepatitis C virus infection. Nat Rev Immunol (2005) 5(3):215-29. doi:10.1038/ nri1573

7. Webster GJ, Reignat S, Brown D, Ogg GS, Jones L, Seneviratne SL, et al. Longitudinal analysis of $\mathrm{CD}^{+} \mathrm{T}$ cells specific for structural and nonstructural hepatitis B virus proteins in patients with chronic hepatitis B: implications for immunotherapy. J Virol (2004) 78(11):5707-19. doi:10.1128/JVI.78.11. 5707-5719.2004

8. Boni C, Fisicaro P, Valdatta C, Amadei B, Di Vincenzo P, Giuberti T, et al. Characterization of hepatitis B virus (HBV)-specific T-cell dysfunction in chronic HBV infection. J Virol (2007) 81(8):4215-25. doi:10.1128/JVI. 02844-06

9. Park J-J, Wong DK, Wahed AS, Lee WM, Feld JJ, Terrault N, et al. Hepatitis B virus-specific and global T-cell dysfunction in chronic hepatitis B. Gastroenterology (2016) 150(3):684-95.e5. doi:10.1053/j.gastro.2015.11.050

10. Chang JJ, Thompson AJ, Visvanathan K, Kent SJ, Cameron PU, Wightman F, et al. The phenotype of hepatitis B virus-specific $\mathrm{T}$ cells differ in the liver and
FIGURE S3 | Comparisons of the $\mathrm{V} \beta$ segments usage in peripheral CD4 and CD8 T cells in the complete response (CR) and non-complete response (NCR) patient groups during early NUC treatment. Different usage of the $V \beta$ gene segments in CD4 (A) and CD8 (B) T cells in the CR and NCR patient groups (all $P$-values $<0.05$, Mann-Whitney $U$ tests). The fold change is calculated as the frequency of indicated $V \beta$ gene segment in $C R$ group divided by the frequency of corresponding $\mathrm{V} \beta$ gene segment in the NCR group at the same time point. BL, baseline; W12, week 12; W24, week 24.

FIGURE S4 | Principal component analysis of $\mathrm{V} \beta$ gene segment usage in CD4 and CD8 T cells. Principal component analysis shows the usage patterns of $\vee \beta$ gene segments of $C D 4$ (A) and CD8 (B) samples of complete response (CR) group patients (red dots) and non-complete response (NCR) group patients (blue dots). PC1 refers to the first principal component, whereas PC2 indicates the second principal component.

FIGURE S5 | Fluctuations of overall CD4 and CD8 clone repertoires in different groups. Longitudinal data points from each clonotype in each patient are connected by a line (frequency increased, red line; frequency decreased, blue line, frequency constant, green line). The log10-transformed frequency is indicated on the $y$-axis. The $x$-axis represents treatment timepoints. BL, baseline; W12, week 12; W24, week 24.

FIGURE S6 | Tracking the dominant clones over the treatment. The top5 (A,B), top 10 (C,D), top 20 (E,F), top $50(\mathbf{G}, \mathbf{H})$ clonotypes in CD4 (left) and CD8 (right) subsets in each patient [complete response (CR) group, upper lane; non-complete response (NCR) group, lower lane] are listed, respectively, and tracking them according to their frequency ( $y$-axis) at baseline, week 12, and 24 (x-axis). Identical clonotypes are connected by a line (frequency increased, red line; frequency decreased, green line).

blood in chronic hepatitis B virus infection. Hepatology (2007) 46(5):1332-40. doi:10.1002/hep.21844

11. Boni C, Penna A, Bertoletti A, Lamonaca V, Rapti I, Missale G, et al. Transient restoration of anti-viral $\mathrm{T}$ cell responses induced by lamivudine therapy in chronic hepatitis B. J Hepatol (2003) 39(4):595-605. doi:10.1016/ S0168-8278(03)00292-7

12. Boni C, Penna A, Ogg GS, Bertoletti A, Pilli M, Cavallo C, et al. Lamivudine treatment can overcome cytotoxic T-cell hyporesponsiveness in chronic hepatitis B: new perspectives for immune therapy. Hepatology (2001) 33(4): 963-71. doi:10.1053/jhep.2001.23045

13. Cooksley H, Chokshi S, Maayan Y, Wedemeyer H, Andreone P, Gilson R, et al. Hepatitis B virus e antigen loss during adefovir dipivoxil therapy is associated with enhanced virus-specific $\mathrm{CD} 4^{+} \mathrm{T}$-cell reactivity. Antimicrob Agents Chemother (2007) 52(1):312-20. doi:10.1128/AAC.00467-07

14. Evans A, Riva A, Cooksley H, Phillips S, Puranik S, Nathwani A, et al. Programmed death 1 expression during antiviral treatment of chronic hepatitis B: impact of hepatitis B e-antigen seroconversion. Hepatology (2008) 48(3):759-69. doi:10.1002/hep.22419

15. Chen Y, Li X, Ye B, Yang X, Wu W, Chen B, et al. Effect of telbivudine therapy on the cellular immune response in chronic hepatitis B. Antiviral Res (2011) 91(1):23-31. doi:10.1016/j.antiviral.2011.04.008

16. TrehanPati N, Kotillil S, Hissar SS, Shrivastava S, Khanam A, Sukriti S, et al. Circulating Tregs correlate with viral load reduction in chronic HBVtreated patients with tenofovir disoproxil fumarate. J Clin Immunol (2011) 31(3):509-20. doi:10.1007/s10875-011-9509-7

17. Wursthorn K, Jung M, Riva A, Goodman ZD, Lopez P, Bao W, et al. Kinetics of hepatitis B surface antigen decline during 3 years of telbivudine treatment in hepatitis B e antigen-positive patients. Hepatology (2010) 52(5):1611-20. doi:10.1002/hep. 23905

18. Rehermann B, Bertoletti A. Immunological aspects of antiviral therapy of chronic hepatitis B virus and hepatitis C virus infections. Hepatology (2015) 61(2):712-21. doi:10.1002/hep.27323

19. Boni C, Laccabue D, Lampertico P, Giuberti T, Vigan M, Schivazappa S, et al. Restored function of HBV-specific T cells after long-term effective therapy with nucleos(t)ide analogues. Gastroenterology (2012) 143(4):963-73.e9. doi:10.1053/j.gastro.2012.07.014 
20. Woodsworth DJ, Castellarin M, Holt RA. Sequence analysis of T-cell repertoires in health and disease. Genome Med (2013) 5(10):98. doi:10.1186/ gm502

21. Davis MM, Bjorkman PJ. T-cell antigen receptor genes and T-cell recognition. Nature (1988) 334(6181):395-402. doi:10.1038/334395a0

22. Rubtsova K, Scott-Browne JP, Crawford F, Dai S, Marrack P, Kappler JW. Many different Vbeta CDR3s can reveal the inherent MHC reactivity of germline-encoded TCR V regions. Proc Natl Acad Sci U S A (2009) 106(19): 7951-6. doi:10.1073/pnas.0902728106

23. Turner SJ, La Gruta NL, Kedzierska K, Thomas PG, Doherty PC. Functional implications of T cell receptor diversity. Curr Opin Immunol (2009) 21(3): 286-90. doi:10.1016/j.coi.2009.05.004

24. Wang GC, Dash P, McCullers JA, Doherty PC, Thomas PG. T cell receptor alphabeta diversity inversely correlates with pathogen-specific antibody levels in human cytomegalovirus infection. Sci Transl Med (2012) 4(128):128ra42. doi:10.1126/scitranslmed.3003647

25. van Heijst JWJ, Ceberio I, Lipuma LB, Samilo DW, Wasilewski GD, Gonzales AMR, et al. Quantitative assessment of T cell repertoire recovery after hematopoietic stem cell transplantation. Nat Med (2013) 19(3):372-7. doi: $10.1038 / \mathrm{nm} .3100$

26. Muraro PA, Robins H, Malhotra S, Howell M, Phippard D, Desmarais C, et al. $\mathrm{T}$ cell repertoire following autologous stem cell transplantation for multiple sclerosis. J Clin Invest (2014) 124(3):1168-72. doi:10.1172/JCI71691

27. Conrad JA, Ramalingam RK, Duncan CB, Smith RM, Wei J, Barnett L, et al. Antiretroviral therapy reduces the magnitude and $\mathrm{T}$ cell receptor repertoire diversity of HIV-specific $\mathrm{T}$ cell responses without changing $\mathrm{T}$ cell clonotype dominance. J Virol (2012) 86(8):4213-21. doi:10.1128/JVI.06000-11

28. Yang J, Chen J, He J, Xie Y, Zhu Y, Cao H, et al. Profiling the repertoire of T-cell receptor beta-chain variable genes in peripheral blood lymphocytes from subjects who have recovered from acute hepatitis B virus infection. Cell Mol Immunol (2014) 11(4):332-42. doi:10.1038/cmi.2014.22

29. Sing GK, Li D, Chen X, Macnaughton T, Lichanska AM, Butterworth L, et al. A molecular comparison of $\mathrm{T}$ lymphocyte populations infiltrating the liver and circulating in the blood of patients with chronic hepatitis B: evidence for antigen-driven selection of a public complementarity-determining region 3 (CDR3) motif. Hepatology (2001) 33(5):1288-98. doi:10.1053/jhep.2001. 24026

30. Yao XS, Zhang GW, Ma L, Wen Q, Hou JL, Meng MJ, et al. Analysis of the CDR3 length of TCR alphabeta T cells in the peripheral blood of patients with chronic hepatitis B. Hepatol Res (2006) 35(1):10-8. doi:10.1016/j.hepres. 2006.01 .006

31. Yang J, He J, Lu H, Wei L, Li S, Wang B, et al. Molecular features of the complementarity determining region 3 motif of the $\mathrm{T}$ cell population and subsets in the blood of patients with chronic severe hepatitis B. J Transl Med (2011) 9(8):210. doi:10.1186/1479-5876-9-210

32. Yang J, Lu H, Guo R, Ye P, Jin L, Chen C, et al. Molecular profile of the T cell receptor beta variable in peripheral blood lymphocytes from chronic asymptomatic HBV carriers. Pathog Dis (2014) 73(2):1-5. doi:10.1093/femspd/ $\mathrm{ftu} 018$

33. Yang J, Chen J, Mao H, Yi P, Yan D, He J, et al. Skewed T-cell receptor beta chain variable gene (TCRBV) usage among different clinical types of patients with chronic HBV infection. FEMS Immunol Med Microbiol (2012) 65(3):448-55. doi:10.1111/j.1574-695X.2012.00969.x

34. Ma SW, Li YY, Zhang GW, Huang X, Sun J, Li C, et al. Complementaritydetermining region 3 size spectratypes of $\mathrm{T}$ cell receptor chains in $\mathrm{CD}^{+}$ $\mathrm{T}$ cells following antiviral treatment of chronic hepatitis B. Antimicrob Agents Chemother (2011) 55(2):888-94. doi:10.1128/AAC.01232-10

35. Yang J, Sheng G, Xiao D, Shi H, Wu W, Lu H, et al. The frequency and skewed T-cell receptor beta-chain variable patterns of peripheral $\mathrm{CD}^{+} \mathrm{CD} 25^{+}$ regulatory T-cells are associated with hepatitis $\mathrm{B}$ e antigen seroconversion of chronic hepatitis B patients during antiviral treatment. Cell Mol Immunol (2016) 13(5):678-87. doi:10.1038/cmi.2015.100
36. Huang Y, Ma H, Wei S, Luo G, Sun R, Fan Z, et al. Analysis of the complementarity determining regions beta-chain genomic rearrangement using high-throughput sequencing in periphery cytotoxic T lymphocytes of patients with chronic hepatitis B. Mol Med Rep (2016) 14(1):762-8. doi:10.3892/ mmr.2016.5329

37. Qu Y, Huang Y, Liu D, Huang Y, Zhang Z, Mi Z, et al. High-throughput analysis of the $\mathrm{T}$ cell receptor beta chain repertoire in PBMCs from chronic hepatitis B patients with HBeAg seroconversion. Can J Infect Dis Med Microbiol (2016) 2016:1-7. doi:10.1155/2016/8594107

38. Sun J, Xie Q, Tan D, Ning Q, Niu J, Bai X, et al. The 104-week efficacy and safety of telbivudine-based optimization strategy in chronic hepatitis B patients: a randomized, controlled study. Hepatology (2014) 59(4):1283-92. doi:10.1002/ hep. 26885

39. Fan R, Sun J, Yuan Q, Xie Q, Bai X, Ning Q, et al. Baseline quantitative hepatitis $\mathrm{B}$ core antibody titre alone strongly predicts $\mathrm{HBeAg}$ seroconversion across chronic hepatitis $B$ patients treated with peginterferon or nucleos(t)ide analogues. Gut (2016) 65(2):313-20. doi:10.1136/gutjnl-2014308546

40. Chen Y, Xu Y, Zhao M, Liu Y, Gong M, Xie C, et al. High-throughput T cell receptor sequencing reveals distinct repertoires between tumor and adjacent non-tumor tissues in HBV-associated HCC. Oncoimmunology (2016) 5(10):e1219010. doi:10.1080/2162402X.2016.1219010

41. Bolotin DA, Poslavsky S, Mitrophanov I, Shugay M, Mamedov IZ, Putintseva EV, et al. MiXCR: software for comprehensive adaptive immunity profiling. Nat Methods (2015) 12(5):380-1. doi:10.1038/nmeth.3364

42. Greiff V, Miho E, Menzel U, Reddy ST. Bioinformatic and statistical analysis of adaptive immune repertoires. Trends Immunol (2015) 36(11):738-49. doi:10.1016/j.it.2015.09.006

43. Kumar S, Stecher G, Tamura K. MEGA7: molecular evolutionary genetics analysis version 7.0 for bigger datasets. Mol Biol Evol (2016) 33(7):1870-4. doi:10.1093/molbev/msw054

44. de Niet A, Stelma F, Jansen L, Sinnige MJ, Remmerswaal EB, Takkenberg RB, et al. Restoration of $\mathrm{T}$ cell function in chronic hepatitis $\mathrm{B}$ patients upon treatment with interferon based combination therapy. J Hepatol (2016) 64(3): 539-46. doi:10.1016/j.jhep.2015.10.013

45. Ma SW, Huang X, Li YY, Tang LB, Sun XF, Jiang XT, et al. High serum IL-21 levels after 12 weeks of antiviral therapy predict HBeAg seroconversion in chronic hepatitis B. J Hepatol (2012) 56(4):775-81. doi:10.1016/j. jhep.2011.10.020

46. Li Y, Ma S, Tang L, Li Y, Wang W, Huang X, et al. Circulating chemokine (C-X-C motif) receptor $5^{+} \mathrm{CD} 4^{+} \mathrm{T}$ cells benefit hepatitis $\mathrm{B}$ e antigen seroconversion through IL-21 in patients with chronic hepatitis B virus infection. Hepatology (2013) 58(4):1277-86. doi:10.1002/hep.26489

47. Bertoletti A, Ferrari C. Adaptive immunity in HBV infection. J Hepatol (2016) 64(1 Suppl):S71-83. doi:10.1016/j.jhep.2016.01.026

48. Kah J, Koh S, Volz T, Ceccarello E, Allweiss L, Lutgehetmann M, et al. Lymphocytes transiently expressing virus-specific $\mathrm{T}$ cell receptors reduce hepatitis B virus infection. J Clin Invest (2017) 127(8):3177-88. doi:10.1172/ JCI93024

Conflict of Interest Statement: The authors declare that the research was conducted in the absence of any commercial or financial relationships that could be construed as a potential conflict of interest.

Copyright $\odot 2017$ Xu, Liu, Zhao, Chen, Xie, Gong, Deng, Li, Sun, Hou, Wu and Wang. This is an open-access article distributed under the terms of the Creative Commons Attribution License (CC BY). The use, distribution or reproduction in other forums is permitted, provided the original author(s) or licensor are credited and that the original publication in this journal is cited, in accordance with accepted academic practice. No use, distribution or reproduction is permitted which does not comply with these terms. 